\title{
Burden and correlates of disability and functional impairment in an urban community
}

Introduction: The risk of developing chronic diseases and general disability increases with aging, resulting in loss of functioning ability and decrease in performing optimally. Early diagnosis of impairment and disability may improve the quality of life of elderly and enable them to lead a full and productive life. The study is a part of a larger study done in an urban area of Delhi. Materials and Methods: Systematic random sampling was used to select a cross-sectional sample of the study subjects $>20$ years and above. Locomotor, Visual Hearing and Speech were assessed using the guidelines given in gazette of India, extraordinary, part II section. Visual disability was measured by the presenting visual acuity in the field area using Snellens chart using WHO guidelines. Result and Conclusion: A total of 120 study subjects out of 1300 screened were in geriatric age group. The overall magnitude of the physical disability was $43.3 \%$ among elderly. Visual disability was most common form of disability (60\%). Many study subjects were suffering from $>1$ disability, but treatment was sought only in $50 \%$ of disabilities. Treatment seeking for disabilities is an important and neglected issue leading to severe degree of disabilities that would be prevented if taken care of, in due time. A multidimensional approach for prevention is the need of the hour.

Key words: Impairment, physical disability, treatment seeking, visual disability

\section{BACKGROUND}

Anika Sulania, Jyoti Khandekar', Seetharamiah Nagesh

Department of Community

Medicine, Jamia Hamdard, Hamdard Institute, 'Department of Community Medicine, Lady Hardinge Medical College,

New Delhi, India

Address for the Correspondence:

Dr. Anika Sulania

Ja-23, UGF, Khirki Extension, Malviya Nagar, New Delhi - 110017

India.

E-mail: Ani.sulania@gmail.com

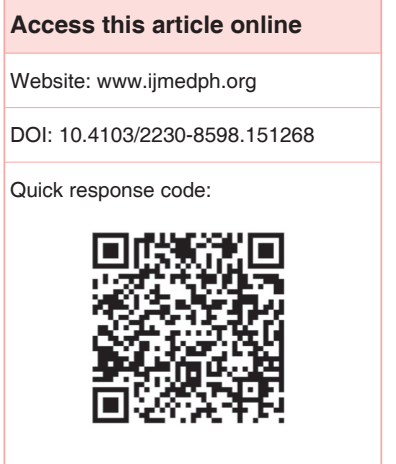

It has been projected that by the year 2025 , there will be 1.2 billion older persons, with two out of three living in a developing country. ${ }^{[1]}$ In the next few years, for the $1^{\text {st }}$ time, there will be more people in the world aged over 60 than children aged $<5$. By 2050, 80\% of the world's older people will be living in low- and middle-income countries. ${ }^{[2]}$

With increasing age, there is a concomitant increase in chronic conditions and greater dependency on caregivers. The elderly have different needs as they have higher morbidities, are more vulnerable and with higher dependency. An assessment of elderly's health needs a comprehensive examination and prevention needs a multidimensional approach.

Limited literature is available about the extent of disability among elderly, especially in developing countries. It is important to understand the causes of disabilities among the population and to frame a better health care policy, programs and related measures that may reduce the burden of diseases. Therefore this study is planned to explore the pattern of disability and related treatment and rehabilitation seeking behavior in geriatric population keeping the focus on the key issues of disability and the pattern of disability related treatment and rehabilitation seeking behavior among geriatric population in an urban area of Delhi.

\section{MATERIALS AND METHODS}

This study was a part of a community based cross-sectional study carried out from October 2010 to March 2012 in an urban area of South West district of Delhi, which serves as one of the field practice area for training of undergraduate and postgraduate students of Department of Community Medicine of a teaching tertiary care institution.

The population of this area was enlisted by house to house survey. The total population of the area is 7200 , residing in 1200 households. The area is a mix of residential units and business establishments with population 
belonging to different socio-economic strata and regions. The data collection for this study was done in calendar year of 2011. People aged $>60$ years were considered as elderly for the purpose of study and elderly of both sexes formed the study population. A sample size of 77 was calculated with $30 \%$ prevalence of any disability, 95\% confidence interval and $10 \%$ standard error. A design effect of 1.5 was added to reach an effective sample size of 116 finally 120 subjects were included in the study.

Systematic random sampling was used for enrolment of study subjects. First house was selected randomly after that every third household was visited for the purpose of the study to cover the whole population. All the members of the household were screened for presence of disability and detailed examination was carried out of all subjects with disability using a pre designed, pretested semi structured interview schedule Measurement of Disability ${ }^{[3]}$ was based on the basis of the guidelines given in Gazette of India extraordinary part 2 section 1 except visual disability, which was measured by the presenting visual acuity in the field area using Snellens chart using WHO guidelines. ${ }^{[4]}$ Subjects with disability were referred for specialist care. Throughout the study, subjects were ensured of privacy and confidentiality. Statistical Analysis of data was performed using SPSS version 12 (SPSS Inc., IBM, Chicago). The study has been approved from the institutional ethical committee of the institution and the written consent was taken by each and every subject before filling the proforma.

\section{RESULTS}

Of total 1300 study subjects who were screened 120 subjects were in geriatric age group and were included in the final analysis. $52.5 \%$ of study subjects were females Majority of the study population $(62.5 \%)$ belonged to 60-69 years of age group, $65.0 \%$ of the study subjects were married. $34.2 \%$ were widow(er) s and $55.6 \%$ were illiterate. Majority $(86.7 \%)$ of the study population belonged to Hindu religion, and $(78.3 \%)$ lived in joint family system. More than one-third (42.5\%) of the study population belonged to upper lower socioeconomic class followed by lower middle $(29.2 \%)$ as shown in Table 1.

Of 120 study subjects, 30 (25\%) were free of any disability, 38 (32\% had functional impairment) and $52(43.3 \%)$ were having some or other type of physical disability [Figure 1]. More than one-third of males were free of disability as compared to only $20 \%$ of women. Multiple disabilities were also found resulting in $>1$ disability per

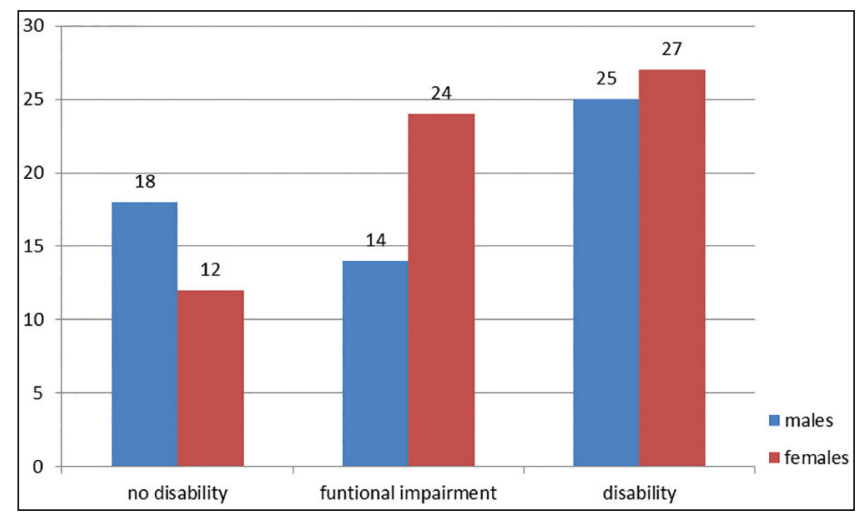

Figure 1: Disability among the study population subject. Out of all the physical disabilities, visual disability was commonest (60\%) followed by locomotor disability (39\%) [Figure 2]. The prevalence of disability increased with age. None of the study subjects aged 80 years and above was free of disability [Figure 3].

It was found that the most common cause was Cataract followed by disability due to age related morbidities [Figure 4]. Out of total 60 disabilities found in 120 subjects, treatment was sought only for $57 \%$ of disabilities. Treatment seeking behavior for all the disabilities was more in males (51.3\%) as compared to women (40\%). Treatment was sought more for visual (58\%) and locomotor $(62.5 \%)$ disabilities. Of all disabilities treatment seeking behavior was least for hearing disability, however, once initiated more than two-third of patients completed the treatment and rehabilitation process [Figure 5].

\begin{tabular}{|c|c|c|c|}
\hline \multirow[t]{2}{*}{ Age (in completed years) } & \multicolumn{2}{|c|}{ Sex } & \multirow[t]{2}{*}{ Total (\%) } \\
\hline & Male (\%) & Female (\%) & \\
\hline $60-69$ & $34(59.6)$ & $41(65.1)$ & $75(62.5)$ \\
\hline $70-79$ & $20(35.1)$ & $15(23.8)$ & $35(29.2)$ \\
\hline $80-89$ & $2(3.5)$ & $5(7.9)$ & $7(5.8)$ \\
\hline $90-99$ & $1(1.8)$ & $2(3.2)$ & $3(2.5)$ \\
\hline \multicolumn{4}{|l|}{ Marital status } \\
\hline Unmarried & $0(0)$ & $1(1.6)$ & $1(0.8)$ \\
\hline Married & $41(71.9)$ & $37(58.7)$ & $78(65)$ \\
\hline Widow/widower & $16(28.1)$ & $25(39.7)$ & $41(34.2)$ \\
\hline \multicolumn{4}{|l|}{ Religion } \\
\hline Hindu & $49(86)$ & $55(87.3)$ & $104(86.7)$ \\
\hline Muslim & $6(10.5)$ & $5(7.9)$ & $11(9.2)$ \\
\hline Sikh & $2(3.5)$ & $3(4.8)$ & $5(4.2)$ \\
\hline \multicolumn{4}{|l|}{ Literacy status } \\
\hline Literate & $21(36.8)$ & $17(27)$ & $38(31.7)$ \\
\hline Illiterate & $36(63.2)$ & $46(73)$ & $82(68.4)$ \\
\hline \multicolumn{4}{|l|}{ Type of family } \\
\hline Nuclear & $9(15.8)$ & $17(27)$ & $26(21.7)$ \\
\hline Joint & $48(84.2)$ & $46(73)$ & $94(78.3)$ \\
\hline \multicolumn{4}{|c|}{$\begin{array}{l}\text { Socioeconomic status (modified } \\
\text { Kuppuswamy scale CPI 2012) }\end{array}$} \\
\hline Upper & $1(1.8)$ & $3(4.8)$ & $4(3.3)$ \\
\hline Upper middle & 7 (12.3) & $13(20.6)$ & $20(16.7)$ \\
\hline Lower middle & $19(33.3)$ & $16(25.4)$ & $35(29.2)$ \\
\hline Upper lower & $28(49.1)$ & $23(36.5)$ & $51(42.5)$ \\
\hline Lower & $2(3.5)$ & $8(12.7)$ & $10(8.3)$ \\
\hline Total & $57(47.5)$ & $63(52.5)$ & $120(100)$ \\
\hline
\end{tabular}

$\mathrm{CPI}=$ Community periodontal index

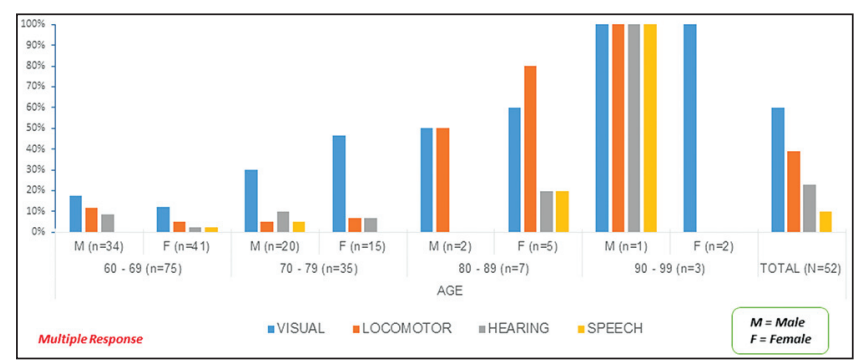

Figure 2: Types of disability in elderly 


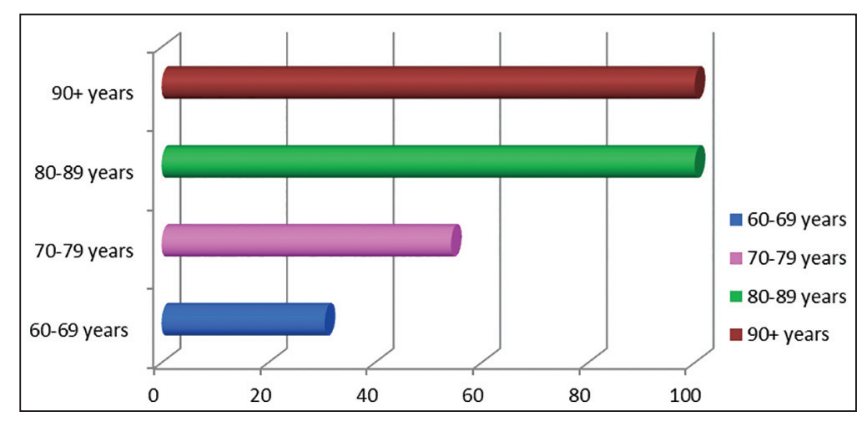

Figure 3: Age and physical disability

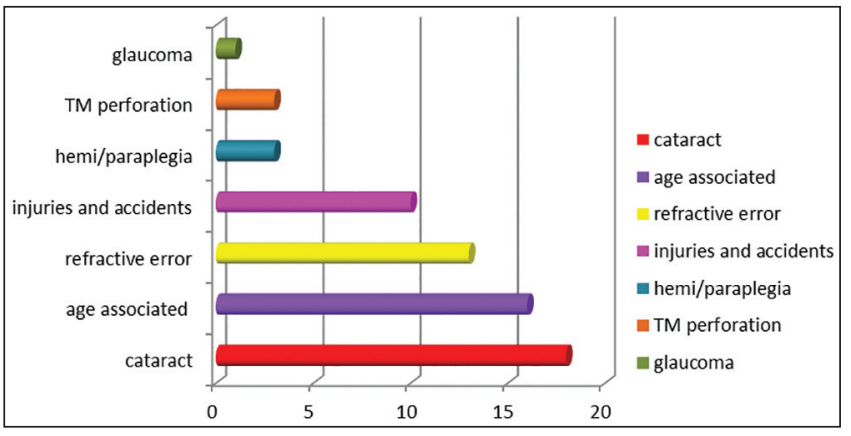

Figure 4: Causes of disability

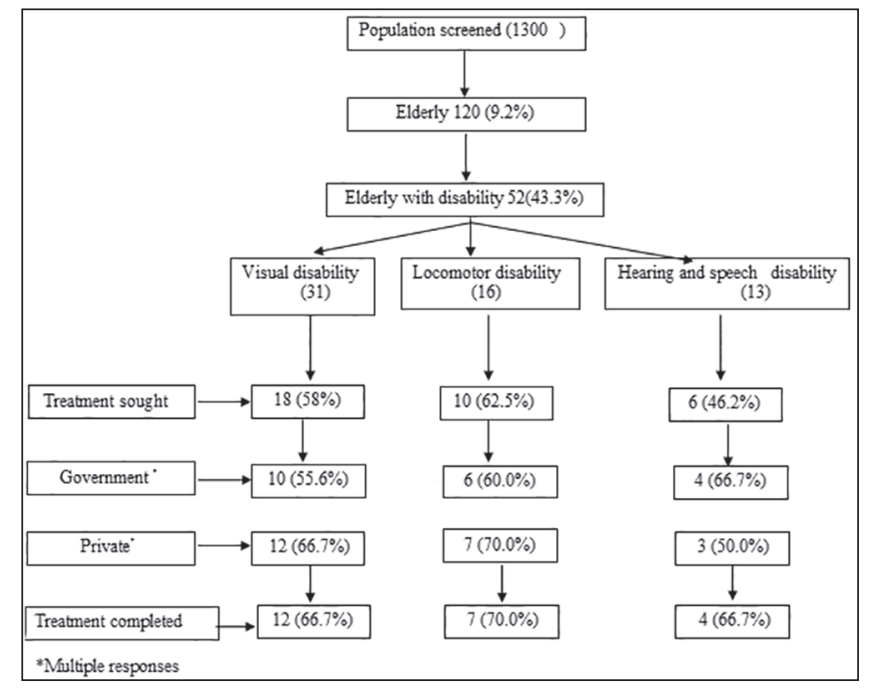

Figure 5: Treatment seeking for disability

\section{DISCUSSION}

The aging population in India is growing rapidly, and this group has the higher number of impairment and disabilities. The limited availability and poor access to the health services for elderlies compound the problem.

The proportion of elderlies decreased with advancing age with maximum numbers of study subjects in the age group of 60-69 years $(62.5 \%)$ and $52.5 \%$ were women. Majority stayed in joint families (78.3) and $68.4 \%$ of the study subjects were illiterate. Roughly 40\% subjects elderlies belonged to upper lower socioeconomic status [Table 1].
The prevalence of disability found in our study is higher (6.7\%) when compared to other studies. ${ }^{[3-6]}$ The difference may be explained on the basis of the different definition of disability used and the fact that in the present study, screening and examination were performed by a qualified investigator. And specialized test like audiometry were done for accurate diagnosis.

Most of the out of 120 study subjects 52 (43.3\%) of the study subjects were suffering from one or another type of disability. In our study, age-wise disability prevalence ratio was also taken into account, and it was found that the prevalence of disability increased with age. All the study subjects 80 years and above have some or other physical disability. Similar findings were reported by Sagar et al. ${ }^{[7]}$ and Singh..$^{[8]}$

Out of all the physical disabilities visual disability was found to be highest (60\%) followed by locomotor disability (39\%). Proportion of disabilities altogether was higher in females as compared to males. Verbrugge explains that men are more likely than women to encounter a series of chronic illness that increases the risk of mortality, such as coronary heart disease, atherosclerosis, and emphysema..$^{[9]}$ Conversely, women are more likely than men to encounter chronic diseases that are physically limiting, but not lifethreatening. Disabilities were found to be significantly associated with lower socioeconomic status, joint family, and illiteracy. Padhyegurjar SB et al. (2008) reported that the prevalence of loco motor disabilities was $5.59 \%$. However among the affected individuals, $71.22 \%$ were females. ${ }^{[10]}$

Regarding the treatment seeking behavior of the study subjects, in total treatment was sought maximum for locomotor disability pointing that locomotor disability is the most limiting disability making subjects to sought the treatment as soon as possible. Treatment was sought least for hearing disability, which may be attributed to perceived chronic nature of the problem and part of natural ageing process. Numerous studies have found gender differences not only in the various steps in the main pathway leading to disability, but also in the way behavioral, external and internal risk factors and treatment seeking behavior associated with disability treatment seeking was more in men for visual disability as in Indian scenario men are bread earner of the family and more attention is paid to their health status. In female's treatment was sought equally for locomotor and hearing disability, however in majority of the study subjects treatment was started when the disability interfered with household work, limiting their capacity to take care of the family rather than causing any difficulty to them. It is worth noting that in Indian Scenario, women ignore their own health, and the role of wife and mother is considered as a primary role for them. In India, disabled women constitute around 42\% of the total disabled population. They are most marginalized in terms of their social, economic, political and health status. Most of the disabilities could have been corrected, provided medical intervention supported by educational and social integration of disabled starts early 


\section{CONCLUSION}

Disability was found to be associated with many factors, so a multidimensional approach is the need of the hour. Locomotor, vision, and hearing disabilities are the most common types of disabilities in the community and rehabilitative and preventive measures should be targeted toward them As treatment seeking is an important and neglected issue which was observed more in females as compared to males, leading to severe degree of disabilities that would be prevented if detected and treated early.

\section{REFERENCES}

1. World Health Organisation. World Population Prospects: The 2000 Revision. Geneva: World Health Organisation; 2001.

2. World Health Organisation. News Release 03. Geneva: World Health Organisation; 2012.

3. Government of India. Guidelines for Evaluation of Various Disabilities and Procedure for Certification. Ministry of Social Justice and Empowerment Notification. New Delhi: $1^{\text {st }}$ June, 2001. Available from: http://www. socialjustice.nic.in. [Last accessed on 2012 Feb 04].
4. World Health Organization. ICD-10 updates 2006. Geneva: World Health Organization. Available from: http://www.who.int/. [Last accessed on 2012 Feb 04].

5. Pati RR. Prevalence and pattern of disability in a rural community in Karnataka. Indian J Community Med 2004;29:37-9.

6. Karkee R, Yadav BK, Chakravartty A, Shrestha DB. The prevalence and characteristics of disability in Eastern Nepal. Kathmandu Univ Med J (KUMJ) 2008;6:94-7.

7. Sagar B, Motghare DD, Venugopalan PP, Kulkarni MS. Study of prevalence and types of disabilities at rural health centre Mandur - A community based cross sectional house to house study in rural Goa. Indian J Phys Med Rehabil 2008;19:56-60.

8. Singh A. Burden of disability in a Chandigarh village. Indian J Community Med 2008;33:113-5.

9. Verbrugge LM. Gender and health: An update on hypotheses and evidence. J Health Soc Behav 1985;26:156-82.

10. Padhyegurjar SB, Padhyegurjar MS. Cross-sectional study of locomotor disabilities in urban slum area of Mumbai. Natl $\mathrm{J}$ Community Med 2011;2:492-93.

How to cite this article: Sulania A, Khandekar J, Nagesh S. Burden and correlates of disability and functional impairment in an urban community. Int J Med Public Health 2015;5:82-5.

Source of Support: Nil, Conflict of Interest: None declared. 